\title{
Postmidnight equatorial plasma irregularities on the June solstice during low solar activity - a case study
}

\author{
Claudia M. N. Candido ${ }^{1,2}$, Jiankui Shi ${ }^{1}$, Inez S. Batista ${ }^{2}$, Fabio Becker-Guedes ${ }^{2}$, Emília Correia ${ }^{2,6}$, \\ Mangalathayil A. Abdu ${ }^{2,4}$, Jonathan Makela ${ }^{3}$, Nanan Balan ${ }^{7}$, Narayan Chapagain ${ }^{5}$, Chi Wang ${ }^{1}$, and Zhengkuan Liu ${ }^{1}$ \\ ${ }^{1}$ National Space Science Center, NSSC, Chinese Academy of Sciences, State Key Laboratory, \\ China-Brazil Joint Laboratory for Space Weather, Beijing, China \\ ${ }^{2}$ National Institute for Space Research - INPE, São José dos Campos, SP, Brazil \\ ${ }^{3}$ Department of Electrical and Computer Engineering, University of Illinois at Urbana-Champaign, \\ Urbana, Illinois 61801, USA \\ ${ }^{4}$ Instituto Tecnológico de Aeronáutica - ITA, São Jose dos Campos, Brazil \\ ${ }^{5}$ Department of Physics, Patan Multiple Campus, Tribhuvan University, Latitpur, Nepal \\ ${ }^{6}$ Centro de Radio Astronomia e Astrofísica Mackenzie, CRAAM, University Presbiteriana Mackenzie, São Paulo, Brazil \\ ${ }^{7}$ Institute of Geology and Geophysics, Chinese Academy of Sciences, Beijing, China
}

Correspondence: Claudia M. N. Candido (claudia.candido@inpe.br)

Received: 11 October 2018 - Discussion started: 28 November 2018

Revised: 6 June 2019 - Accepted: 18 June 2019 - Published: 30 July 2019

\begin{abstract}
We present a case study of unusual spread-F structures observed by ionosondes at two equatorial and low-latitude Brazilian stations - São Luís (SL: $44.2^{\circ} \mathrm{W}$, $2.33^{\circ} \mathrm{S}$; dip angle: $-6.9^{\circ}$ ) and Fortaleza (FZ: $38.45^{\circ} \mathrm{W}$, $3.9^{\circ} \mathrm{S}$; dip angle: $-16^{\circ}$ ). The irregularity structures observed from midnight to postmidnight hours of moderate solar activity $\left(\mathrm{F} 10.7<97 \mathrm{sfu}\right.$, where $\left.1 \mathrm{sfu}=10^{-22} \mathrm{~W} \mathrm{~m}^{-2} \mathrm{~s}^{-1}\right)$ have characteristics different from typical post-sunset equatorial spread F. The spread-F traces first appeared at or above the Flayer peak and gradually became well-formed mixed spread F. They also appeared as plasma depletions in the $630.0 \mathrm{~nm}$ airglow emissions made by a wide-angle imager located at the nearby low-latitude station Cajazeiras (CZ: $38.56^{\circ} \mathrm{W}$, $6.87^{\circ} \mathrm{S}$; dip angle: $\left.-21.4^{\circ}\right)$. The irregularities appeared first over FZ and later over SL, giving evidence of an unusual westward propagation or a horizontal plasma advection. The drift-mode operation available in one of the ionosondes (a digital portable sounder, DPS-4) has enabled us to analyze the horizontal drift velocities and directions of the irregularity movement. We also analyzed the neutral wind velocity measured by a Fabry-Pérot interferometer (FPI) installed at $\mathrm{CZ}$ and discuss its possible role in the development of the irregularities.
\end{abstract}

\section{Introduction}

Equatorial spread F, representing small-scale to large-scale plasma irregularities, has been extensively studied for several decades. Large-scale plasma irregularities, specifically known as equatorial plasma bubbles (EPBs), are known to be associated with equatorial spread F. In the Brazilian equatorial sector, characterized by large negative magnetic declination, spread $\mathrm{F}$ and EPBs have high occurrence rates during local summer and equinoctial months (Abdu et al., 1981a; Sahai et al., 2000; Sobral et al., 2002). However, during low solar activity conditions, there is a class of spread-F and plasma irregularities regularly observed in distinct longitudinal sectors, such as Brazil (Candido et al., 2011), Africa (Yizengaw et al., 2013), and Asia (Nishioka et al., 2012). They are known as postmidnight plasma irregularities (PMIs), which occur mostly in the June solstice. Comprehensive reviews on postmidnight plasma irregularities and plasma irregularities have been recently published by Otsuka (2017) and Balan et al. (2018).

PMIs occur under conditions considered unfavorable for the development of the Rayleigh-Taylor (RT) instability, since at night the vertical plasma drifts are downward owing to the westward electric fields. In recent years, a variety of works have reported their occurrence both at low lat- 
itudes and the equatorial region. Otsuka and Ogawa (2009) and Nishioka et al. (2012) investigated PMIs over Indonesia and discussed their possible sources. Li et al. (2011) reported these irregularities observed over Hainan, China, during low solar activity. Candido et al. (2011) presented a study of PMIs observed over the south crest of the equatorial ionization anomaly (EIA) during low solar activity, in Cachoeira Paulista (CP), Brazil. Yokoyama et al. (2011) studied unusual patterns of echoes from coherent scatter radar data occurring around midnight during the solar minimum period. They observed two principal types of irregularities: upwelling plumes and striations similar to mesoscale traveling ionospheric disturbances (MSTIDs). They have argued that the former can be generated by RT instability (at the equatorial region) or Perkins instability (at the midlatitude region) and the later only by Perkins instability. Yizengaw et al. (2013) presented a study of PMIs over equatorial Africa and also investigated their most probable causes. Dao et al. (2016) reported the occurrence of postmidnight field-aligned irregularities (FAIs) in Indonesia during low solar activity in 2010.

Many instrumental techniques are currently providing high-quality measurements and results for ionospheric studies. Early investigations of the ionosphere observed diffuse echoes in data from measurements using ionosondes, which are high-frequency radars used for ionospheric sounding (Breit and Tuve, 1926; Booker and Wells, 1938). The term "spread F" is widely used to generically refer to the irregularities observed in equatorial and low-latitude regions. Nowadays, digital ionosondes are extensively used for groundbased sounding of the ionosphere, providing information from the $\mathrm{E}$ region to the peak of the $\mathrm{F}$ layer, over a variable range of frequencies as well as features related to the propagation of the irregularities (Reinisch et al., 2004; Batista et al., 2008; Abdu et al., 2009). Equatorial spread F has been extensively studied for several decades, and it is known to be associated with the occurrence of large-scale plasma irregularities or equatorial plasma bubbles (EPBs).

Optical imaging of thermospheric emissions, like that used in this work, is also a useful ground-based technique for studying thermosphere-ionosphere processes. All-sky imaging systems provide images of thermospheric emissions (e.g., OI $630 \mathrm{~nm}$, OI $777.4 \mathrm{~nm}$ emissions) at ionospheric heights over a large horizontal extent. The OI $630 \mathrm{~nm}$ emission comes from recombination processes between molecular oxygen and electrons and presents a volumetric emission rate, which peaks at an altitude of $\sim 250 \mathrm{~km}$ around the $\mathrm{F}$ layer at the bottom-side height. In this way, variations in the intensity of the emission (dark and bright regions) are used as tracers of ionospheric irregularities, such as EPBs, or other disturbances, such as traveling ionospheric disturbances - TIDs (Pimenta et al., 2008; Abalde et al., 2009; Makela et al., 2010; Candido et al., 2011; Chapagain et al., 2012).

For clarity for the present study, which presents a distinct pattern of spread $\mathrm{F}$ from those usually observed in equatorial ionograms, we first address the current state of understanding regarding spread-F signatures in ionosonde data.

It is currently accepted that there are two main spread-F types: range- and frequency-type spread-F traces (Abdu et al., 1998). The range type of spread F, often associated with the occurrence of medium- and large-scale irregularities, including EPBs, is comprised of trace patterns with the echoes spread in range and with the onset beginning at the lowerfrequency end of the F-layer trace in ionograms. During the spread-F season in Brazil between October and March, evening pre-reversal enhancement in the zonal electric field, and therefore in the F-layer vertical drift, attains large values, and the range type of spread $\mathrm{F}$ is observed in equatorial ionograms, followed by their appearance at the crest region of the EIA, which is located around Cachoeira Paulista (CP: $22.4^{\circ} \mathrm{S}, 45^{\circ} \mathrm{W}$; dip angle: $-37^{\circ}$ ). During the remaining part of the year, when the vertical drifts are minimal (Batista et al., 1996), spread F is restricted to the height region below the F-layer peak, rarely reaching the topside ionosphere, and is therefore observed only close to the dip Equator. This type of spread $\mathrm{F}$ is usually classified as bottom-side spread F (Valladares et al., 1983). The other typical spread-F pattern observed in equatorial ionograms is the frequency type of spread F. In this case, the spread-F echoes are seen at frequencies around the F-layer critical frequency $(f o \mathrm{~F} 2)$. It is believed to be associated with smaller-scale decaying irregularities following spread-F EPBs (Abdu et al., 1981b).

Some studies have pointed out that frequency-type spread F can sometimes be associated with patches of ionization propagating eastward (MacDougall et al., 1998). However, other spread-F patterns are frequently observed in solstices in distinct longitudinal sectors as reported in Brazilian (Candido et al., 2011; MacDougall et al., 2011), Asian (Yokoyama et al., 2011), African (Yizengaw et al., 2013), and Peruvian (Zhan et al., 2018) sectors. Also, it is known that both frequency and range spread-F types can appear simultaneously as a mixed spread-F pattern. In this work, we present a case study on an unusual (anomalous) spread-F and plasma irregularity-depletion pattern observed over the equatorial region. We use the term "unusual" in the sense that the observed features are distinct from those typically observed for spread $\mathrm{F}$ associated with post-sunset spread $\mathrm{F}$, as described above. Although the unusual type of spread $\mathrm{F}$ has been recognized since early studies of the equatorial ionosphere (Munro and Heisler, 1956; Heisler, 1958; Calvert and Cohen, 1961; Bowman, 2001), this is the first time that it is reported for the Brazilian equatorial region with simultaneous airglow observations, which reveal important ionospheric characteristics not available when using only ionosonde data. Earlier studies extensively reported the occurrence of anomalies in Flayer traces, such as cusps, F2 forking, and their possible association with TIDs. Calvert and Cohen (1961) presented a comprehensive study of the distinct spread-F patterns. They concluded that the distinct configurations or shapes of spread $F$ were associated with scattering in the vertical east-west 
plane from field-aligned irregularities and that the spread-F pattern depends on the position relative to the ionosonde and the scale sizes of the irregularities.

\section{Data and methods}

\subsection{Digisondes}

We analyzed ionograms from two digisondes (DPS-4) operated at two Brazilian equatorial sites, São Luís (SL; $44.2^{\circ} \mathrm{W}$, $2.33^{\circ} \mathrm{S}$; dip angle: $-6.9^{\circ}$ ) and Fortaleza (FZ; $38.45^{\circ} \mathrm{W}$, $3.9^{\circ} \mathrm{S}$; dip angle: $-16^{\circ}$ ), which are separated in the eastwest direction by $\sim 600 \mathrm{~km}$. Both instruments provided ionograms at a 10 min cadence. The DPS-4 also performs echo directional studies based on Doppler interferometry, which provides information about the drift velocities associated with irregularities. The operation of each digisonde is based on the transmission of pulses at digital frequencies from 1 to $20 \mathrm{MHz}$ that are reflected from the ionosphere at plasma frequencies lower than $f o \mathrm{~F} 2$. The maximum height range of the ionograms can be set at $\sim 700$ or $\sim 1400 \mathrm{~km}$, for which the resolution is $\sim 5$ and $\sim 10 \mathrm{~km}$, respectively. The ionospheric true heights are calculated by an inversion method implemented by the ARTIST software (Reinisch et al., 2005). Manual scaling of the data can be performed by editing the ionograms using the SAO Explorer software (Galkin et al., 2008). The interferometry system used by the digisonde receivers is comprised of four small-spaced antennas for signal reception arranged in a triangle with one antenna at the center. The signals from each antenna are Fourier analyzed to identify echoes with different Doppler frequencies (for more details, see Reinisch et al., 2004). The Drift Explorer software determines the location of the source regions of the spread-F echoes for each Doppler component. The ionograms present a color code showing the direction of echoes that form the spread F. The sky map and drift data collected after the ionogram are derived from the measured Doppler frequency and angle of arrival of reflected echoes. Special processing software enables us to plot sky maps showing the location of all reflection sources. Drift Explorer also provides plots of the drift velocities (zonal, vertical, and meridional components). For more details about digisonde sounding modes and drift measurements, see Reinisch et al. (2005) and references therein.

\subsection{Wide-angle imaging system}

The airglow images of the OI $630 \mathrm{~nm}$ emission used in this study were measured by a Portable Ionospheric Camera and Small-Scale Observatory (PICASSO) wide-angle imaging system deployed at Cajazeiras (CZ: $6.87^{\circ} \mathrm{S}, 38.56^{\circ} \mathrm{W}$; dip angle: $-21.4^{\circ}$ ), located about $\sim 352 \mathrm{~km}$ to the south of FZ. It is a miniaturized imaging system that measures the 630.0 and $777.4 \mathrm{~nm}$ nightglow emissions. Since the $777.4 \mathrm{~nm}$ emission is generally very weak during solar minimum conditions, we use only the $630.0 \mathrm{~nm}$ emission image data for this study. The PICASSO images are captured on a $1024 \times 1024$ Andor DU434 charge-coupled device (CCD) with a spatial resolution of approximately $1 \mathrm{~km}$ (azimuthal) over the entire field of view. The spatial resolution in the radial direction varies from $\sim 1$ to $\sim 5 \mathrm{~km}$ from zenith to the edge of the field of view. The noise contributions from dark current are reduced by cooling the $\mathrm{CCD}$ to at least $-60^{\circ} \mathrm{C}$. The exposure time for each image is $90 \mathrm{~s}$, and dark images are taken frequently to remove noise and read-out biases. For details about the data processing from a similar PICASSO installation, see Makela and Miller (2008).

\subsection{Fabry-Pérot interferometer (FPI)}

FPIs are optical instruments that measure the spectral line shape of the $630.0 \mathrm{~nm}$ emission at around $250 \mathrm{~km}$ of altitude and are very useful to study thermospheric winds from Doppler shifts in the emission's frequency. For more details on the FPI technique, see Fisher et al. (2015) and references therein. Investigation of the departures of the background wind system can be useful to explain possible sources of the F-uplifts associated with late-time RT instability. For this purpose, we analyzed the behavior of the neutral winds over the equatorial region taken from a ground-based FPI installed in $\mathrm{CZ}$.

\section{Observations}

\subsection{Spread F, F-layer height, and plasma densities}

We present a case study of a spread-F event that occurred in the June solstice of 2011 during a geomagnetically quiet $(\Sigma \mathrm{Kp}=11)$ night and low solar activity with mean F10.7 = 97 SFU (SFU is solar flux unit: $10^{-22} \mathrm{~W} \mathrm{~m}^{-2} \mathrm{~Hz}^{-1}$ ). Figure 1 shows a sequence of ionograms on 25-26 July 2011 from 00:40 to 03:10 LT over SL (top panel) and over the FZ low-latitude site (bottom panel); from 25 July 2011 at 22:00 LT to 26 July 2011 01:30 LT, the presence of unusual spread-F patterns is observed. Over SL, the first spread-F trace appears at 01:00 LT at an oblique angle close to or above the F-layer peak at a virtual range of $600 \mathrm{~km}$. Over the next hour, this structure gradually moves closer to the station SL, finally merging with F-layer bottom-side echoes and becoming a well-formed spread-F trace. During the spread-F development, it is possible to observe an apparent small increase in the F-layer heights. Finally, at the end of the spread$\mathrm{F}$ event, around 02:50 LT, we observe a decreased foF2 and the appearance of an Es layer. We notice a very similar evolutionary pattern of the structures in the FZ ionograms as in those obtained from SL. However, the first spread-F traces appeared over FZ around 22:20 LT, much earlier than over the equatorial site, SL. These echoes from FZ lasted for about $3 \mathrm{~h}$. The spread-F echoes gradually move closer to the station or downward to form a well-structured spread-F pattern. 

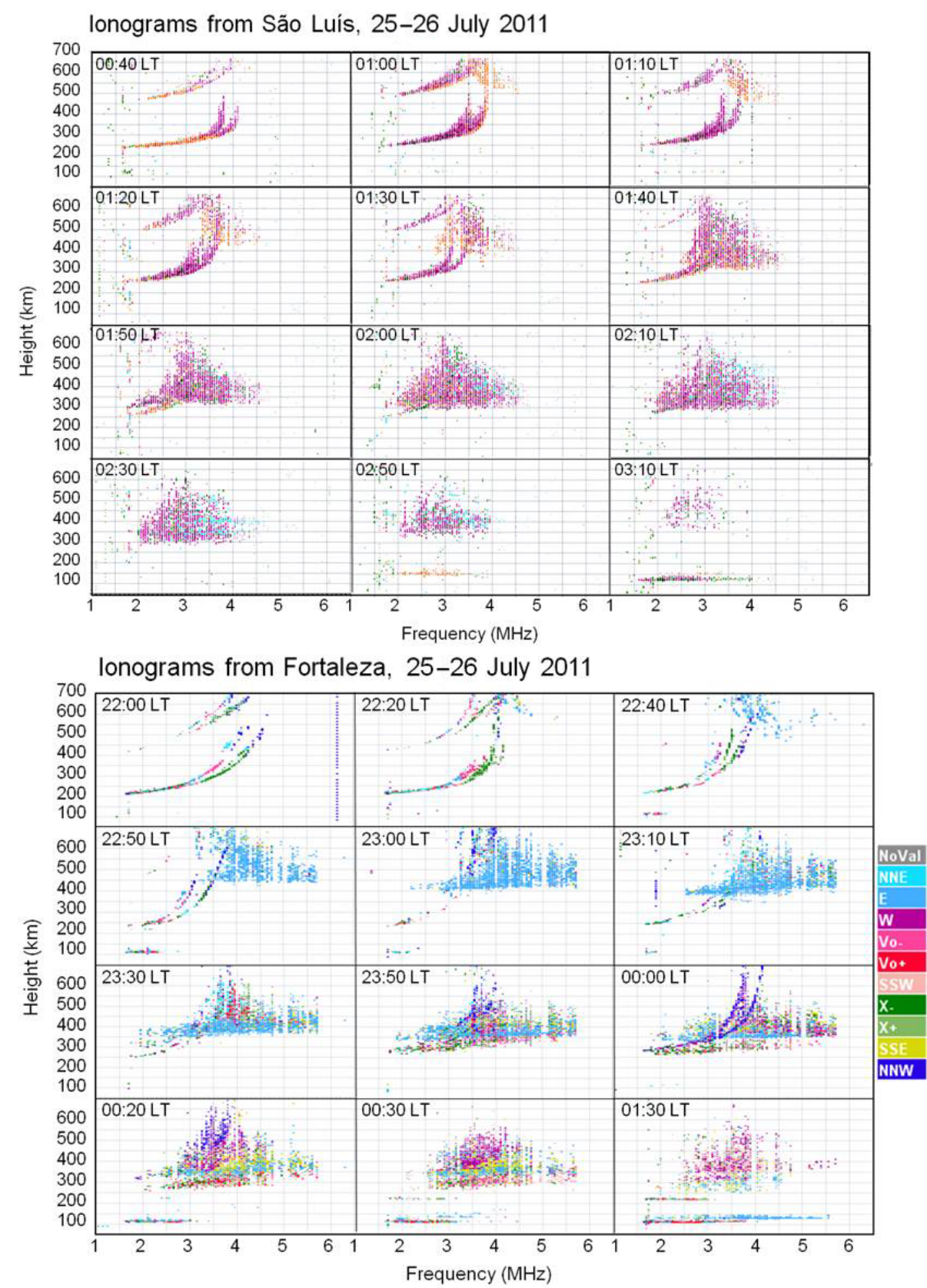

Figure 1. Sequence of ionograms obtained on 25-26 July 2011 at São Luís (SL) from 00:40 to 03:10 LT and over Fortaleza (FZ), Brazil, from 22:00 to 01:30 LT. The spread F shows an unusual pattern, with oblique echoes. The color scale in FZ ionograms indicates that echoes are coming from the east and propagating westward.

An important point to consider is the local ionospheric background in which the spread $\mathrm{F}$ occurred. The F-layer parameters, $h^{\prime} \mathrm{F}$ (virtual height of the F-layer bottom side, in kilometers), $h m \mathrm{~F} 2$ (the real height of the F-layer peak, in kilometers), and $f_{o} \mathrm{~F} 2$ (the F-layer critical frequency; $\mathrm{MHz}$ ) for both stations are shown in Fig. 2 from 18:00 to 06:00 LT. Over SL an uplift of the F layer was observed between 21:00 and 23:00 LT, not associated with any spread-F echoes. Around 21:00 LT at FZ, we may note some wave-like oscil- lations in the F-layer height (notable in $h m \mathrm{~F} 2$ ) with a period on the order of $1 \mathrm{~h}$. The first spread-F trace at oblique angles (and perhaps above the F2 peak) appeared just after these oscillations, as shown by the blue lines connecting the $h^{\prime} \mathrm{F}$ and $h m \mathrm{~F} 2$ curves.

On the other hand, over FZ, where heights are lower than at SL, we observe stronger wave-like oscillations in both $h^{\prime} \mathrm{F}$ and $h m \mathrm{~F} 23 \mathrm{~h}$ earlier than observed at SL. The F-layer critical frequency decreased for both stations, as is expected 


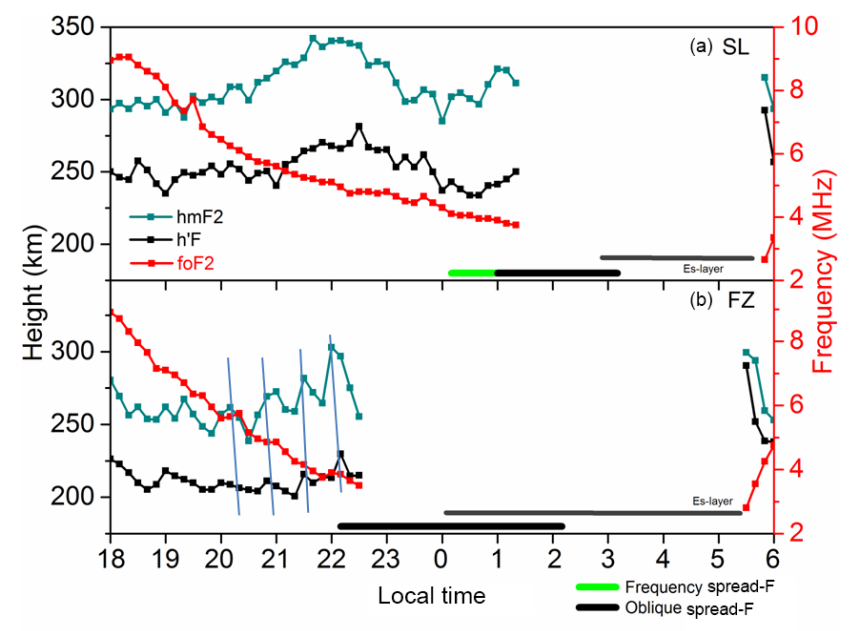

Figure 2. F-layer parameters $h^{\prime} \mathrm{F}(\mathrm{km}), h m \mathrm{~F} 2(\mathrm{~km})$, and $f o \mathrm{~F} 2(\mathrm{MHz})$ on 25-26 July 2011 obtained from the digisondes at SL (a) and FZ (b).

for this period. At the beginning of the spread-F occurrence, the $f o \mathrm{~F} 2$ was as low as $4 \mathrm{MHz}$, corresponding to an electron density of $1.98 \times 10^{5}$ electrons per $\mathrm{cm}^{-3}$. The parameter fxI (not shown), or top frequency of spread $\mathrm{F}$, which is the highest frequency of spread-F echoes, reached values not higher than $4.5 \mathrm{MHz}$ over SL but reached values around $6.0 \mathrm{MHz}$ over FZ, which means a higher plasma density at this region. Moreover, after the spread $\mathrm{F}$ ceased, it was possible to observe the recovery of the plasma frequency and density over FZ sooner than over SL, as shown in both panels around 05:30 LT.

\subsection{Depletions in the airglow OI $630.0 \mathrm{~nm}$ emission}

Figure 3 shows a sequence of four images of the OI $630.0 \mathrm{~nm}$ emission collected on 25-26 July 2011 at Cajazeiras (CZ: center of the frame), Brazil. The images are projected over a geographic map of Brazil assuming an emission altitude of $250 \mathrm{~km}$. The sites of FZ and SL are also indicated in the images for reference. Between 23:12 and 01:26 LT at least two depletions (dark regions passing over FZ and CZ) can be observed propagating westward. These depletions propagated over FZ and CZ at 23:12 LT, in agreement with the spread-F traces seen in the ionograms from FZ.

\subsection{F-layer irregularity drifts - directions and velocities}

Automatic drift-mode routines were used to obtain information about the location of echo sources in the $\mathrm{F}$ layer associated with plasma irregularities. These routines provide information about the distance of the reflected echoes using measurements of the radar ranges to the vertical and oblique echoes as well as their directions, as described by Reinisch et al. (2004). The distribution of the echoes can be displayed
Images of the OI $630 \mathrm{~nm}$ emission from Cajazeiras July 25-26 2011
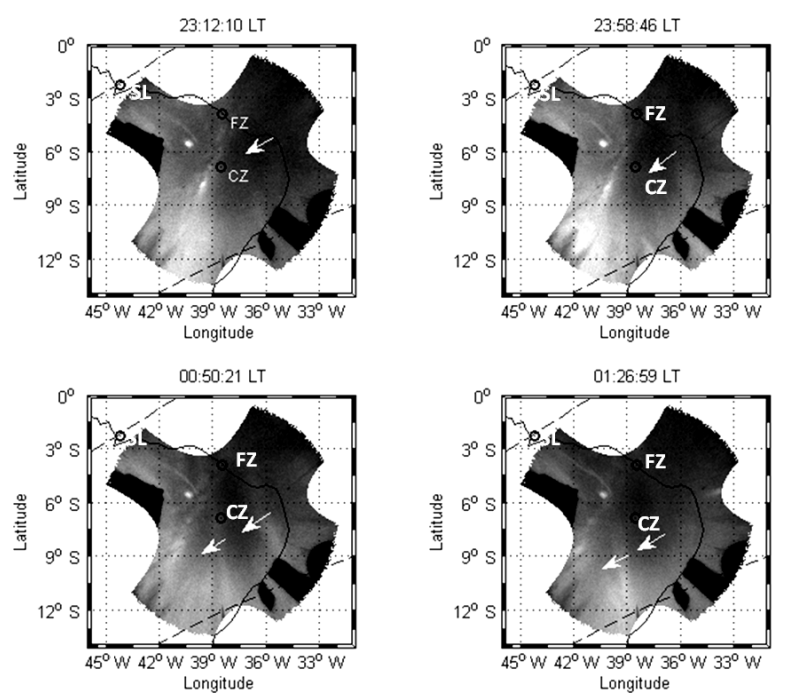

Figure 3. Sequence of OI $630 \mathrm{~nm}$ images showing the time evolution of depletions on 25-26 July 2011 between 23:12 and 01:26 LT at Cajazeiras, Brazil. The images are projected onto geographic coordinates over the Brazil map. In the plot, FZ is Fortaleza, SL is São Luís, and CZ is Cajazeiras. Arrows indicate the propagation direction of the depletions (dark regions passing over FZ and $\mathrm{CZ}$ ).

in sky maps, as shown in Fig. 4. Sky maps between 00:12 and 00:42 LT were constructed using data from FZ during the spread-F event studied; reflected echoes appear and are distributed in a west-east elongated pattern covering a total horizontal distance of $1200 \mathrm{~km}$ (from west to east). It may be noted that, in general, negative Doppler velocity (yellow) of the echoes dominates the western azimuth, while the eastern azimuth is dominated by positive Doppler velocity (blue), a characteristic indicative of an overall westward motion of the irregularity structures. Additional directional information is obtained from the temporal evolution of each spread-F echo in plots of the horizontal distance of the echoes (horizontal axis) as a function of time (vertical axis), presented as directograms. A directogram for the night of 25-26 July 2011 constructed using data from FZ is shown in Fig. 5. Each horizontal line of the directogram corresponds to a single ionogram. The spread echoes are distributed to the east and west of the station mainly from 23:00 to $\sim$ 01:00 LT, although there is a sparse distribution between 21:00 and 23:00 LT. The color codes at both sides indicate the location (east or west) and the incoming and outgoing direction (arrows) of the reflectors (irregularities); for example, the first echoes are seen at the zonal distance of $\sim 320 \mathrm{~km}$ between 23:00 and 23:30 LT coming from the east (red squares). The color code indicates they are to the east of the station coming from the east side. Also, there are echoes to the east of the station that come from the northeast to NNE direction. Among these echoes, there are only a few points that are going eastward (blue points). From 23:30 to 01:30 LT, there are echoes 


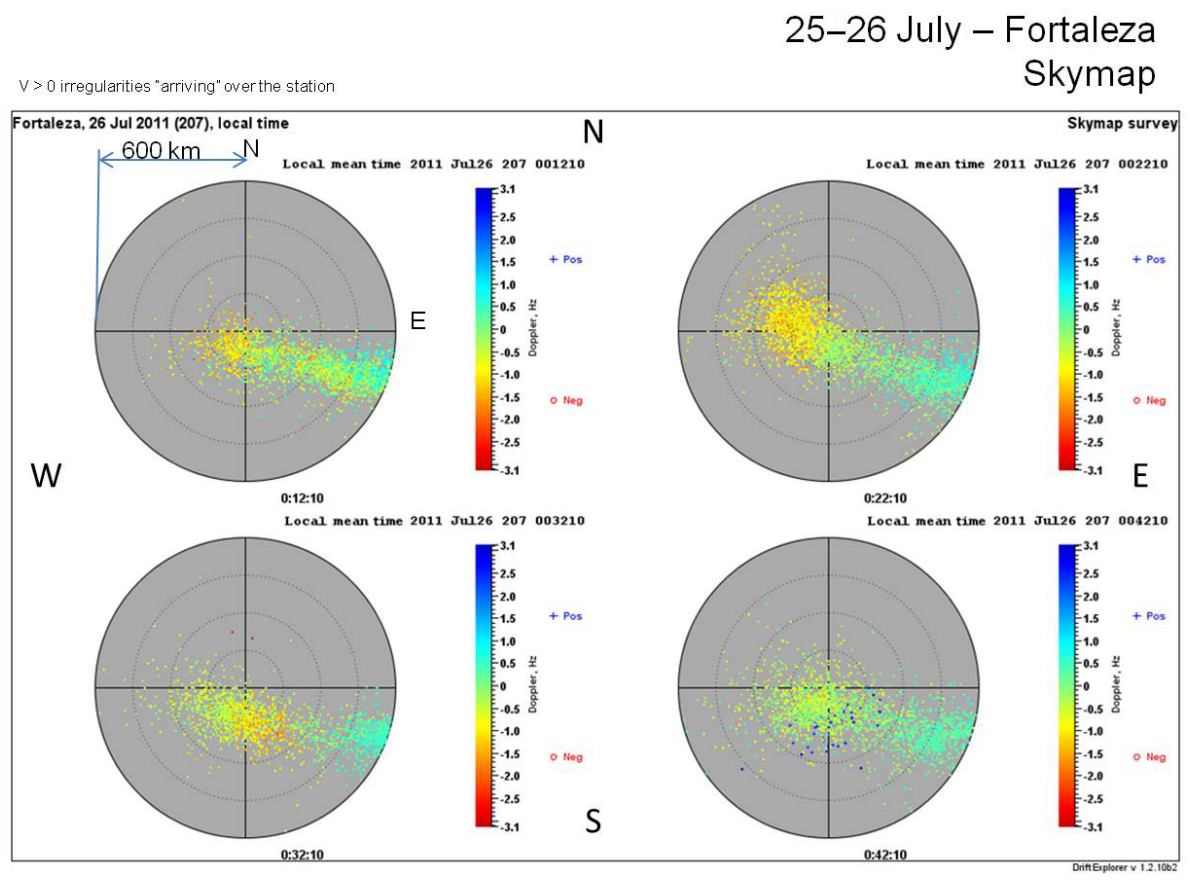

Figure 4. Sky maps registered over FZ from 00:12 to 00:42 LT on 26 July 2011, showing the echo locations and Doppler frequencies (color coded) for F-region echoes from digisondes. Doppler velocities are positive (negative) for irregularities arriving (leaving) the station.

to the west, which gradually disappear after 02:00 LT. The color code to the left shows that they are to the west of the station and going westward. Thus, the echoes present a mean westward propagation. We point out that the horizontal distance range limit is around $600 \mathrm{~km}$, which corresponds to an antenna beam angle of approximately $45^{\circ}$, as is seen in the directograms in Fig. 5, and $h_{\min }$ is the spread-F reflection height.

The unusual spread-F echoes were observed at both equatorial sites, SL and FZ, with a zonal separation of $\sim 600 \mathrm{~km}$. The first spread-F trace was observed at 22:20 LT over FZ and later at 01:00 LT over SL. This lag of $\sim 2 \mathrm{~h} 40 \mathrm{~min}$ suggests an average westward drift velocity component of $\sim 63 \mathrm{~ms}^{-1}$. The DPS-4 drift mode provides the full-vector Doppler velocity for the observed echoes. Figure 6 shows the variation of the $V_{z}$ (vertical component) and $V_{y}$ (zonal component) velocities taken from measurements of the digisonde (DPS-4; drift mode) from 22:00 LT on 25 July 2011 to 04:00 LT on 26 July 2011. Positive (negative) $V_{y}$ velocities represent eastward (westward) propagation. $|V|$ represents the total drift Doppler velocities $\left(<60 \mathrm{~m} \mathrm{~s}^{-1}\right)$, while the maximum vertical upward component is $\sim 30 \mathrm{~m} \mathrm{~s}^{-1}$. The zonal velocities inferred from Drift Explorer agree well with the estimate obtained from the difference in onset times of spread-F echoes between SL and FZ, with a mean value of $\sim 55 \mathrm{~m} \mathrm{~s}^{-1}$ during the event. Figure $6 \mathrm{~b}$ is the vector diagram with the variations of the mean total electrodynamical drift velocity (see Balan et al., 1992). For clarity, the vector length is fixed, and the information on $|V|$ is represented by the con- centric circles (arrow start point). As is observed, the vector is found to rotate anticlockwise, starting in the east-up sector in the night and reaching the west-up sector postmidnight. Velocities extracted from the airglow images obtained from $\mathrm{CZ}$ are shown in Fig. 6c. In order to estimate the velocity of the depletion structure, the individual images were processed by first spatially registering the $630.0 \mathrm{~nm}$ images using the star field. After removing the stars from the images using a point suppression methodology, the images were projected onto geographic coordinates assuming an airglow emission altitude of $250 \mathrm{~km}$ (for details on the analysis technique, see Chapagain et al., 2012). The depletion structure was selected in consecutive images to find the zonal shift of the structures from which the velocity was estimated. The estimated zonal propagation velocity was $\sim 60 \mathrm{~m} \mathrm{~s}^{-1}$, which agrees well with the velocities determined by the Doppler technique of the digisonde. We should keep in mind that the digisonde Doppler technique determines the mean irregularity motion, while the velocities from the airglow technique estimate the mean propagation of the plasma depletion.

Besides the capabilities of the digisonde to sound and detect the occurrence of plasma irregularities seen in the ionograms as spread-F echoes, the F-region height variations, and their vertical drifts, there is a method that uses the true heights to obtain information about gravity wave oscillations at specific plasma frequencies. The true heights are extracted from virtual heights by an inversion algorithm used in the SAO Explore software. This method was described in detail by Abdu et al. (2009) in a comprehensive study about the in- 


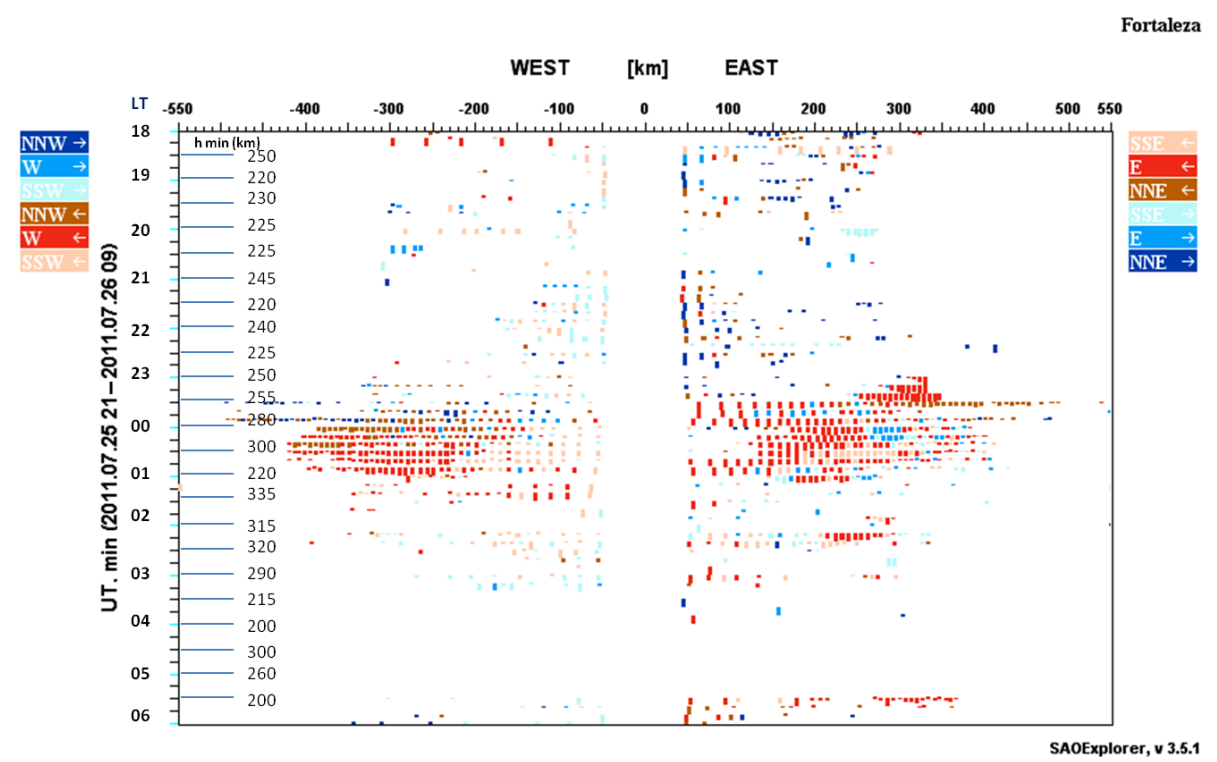

Figure 5. Directogram for Fortaleza on 26 July showing the location and the horizontal distances of the irregularities detected by digisonde and seen in the ionograms as spread F. At left is the F-region height $(\mathrm{km})$, where $h_{\text {min }}$ is the spread-F reflection height. Color code with arrows indicates the direction from which the irregularities are coming or to which the irregularities are moving.

fluence of gravity waves on the equatorial spread F. In their work, the same both locations were analyzed: the off-Equator station FZ and the equatorial station SL. Because both stations are more separated in longitude than in latitude, it was assumed that GW oscillations observed in the bottom-side F layer in FZ could have the same features at SL, considering a few differences attributed to the magnetic field inclination at each one. In this work, we also took advantage of the simultaneous digisonde sounding at these stations in order to verify the possible influence of GWs as a precursor to instability growth, which leads to the late development of the spread F studied.

Figure 7 presents the oscillations in F-layer true height at fixed frequencies $(1.5-5.0 \mathrm{MHz})$ at both stations, SL and FZ. It is possible to observe oscillations prior to the development of spread F, especially in FZ, with periods around $1 \mathrm{~h}$, which will be discussed later in Sect. 4.3.4.

\subsection{Thermospheric winds}

Figure 8 shows the measured thermospheric zonal (top panel) and meridional (bottom panel) wind on 25-26 July, taken from the FPI installed in CZ, the same location where the airglow images were obtained. The shaded region encloses the standard deviation of the monthly average; the green lines are the average winds on 25-26 July $( \pm 2 \mathrm{~d})$, and the red line is the measurement for 25-26 July. It is observed that on 25-26 July between 22:00 and 01:00 LT the zonal wind is abnormally eastward $\left(\sim 100 \mathrm{~m} \mathrm{~s}^{-1}\right)$, while the meridional wind departs from the monthly and daily variation average. From this, we can consider a possible balance between the zonal and meridional wind component to be responsible for plasma advection (plasma movement) from low-latitude to equatorial regions, which might have maintained the $\mathrm{F}$ layer at a higher altitude, as discussed by Nicolls et al. (2006). This apparent uplift observed at both stations around 00:00 LT might have caused the growth of the late RT instability and the PMIs.

\section{Discussion}

We present an unusual event of PMI and spread-F depletions over the equatorial site in Brazil that exhibits singular features. This is the first report of such a distinct pattern of spread $\mathrm{F}$ for the Brazilian equatorial region, though it was observed earlier at the low-latitude station CP (Brazil) for the solar minimum 2008-2009 by Candido et al. (2011). By distinct we mean that it occurs in postmidnight hours propagating westward, which is not usually observed during solar minimum unless there is a previous eastward EPB structure propagation, as mentioned by Paulino et al. (2010). A careful analysis of equatorial ionograms and other plots from digisonde soundings suggests modifications in the ionospheric plasma density structuring, such as those associated with plasma density depletions, which are responsible for a variety of spread-F-layer patterns.

\subsection{Depletions in the airglow OI $630.0 \mathrm{~nm}$ images}

Airglow images show an apparent southwestward propagation of depletions on this night, which differs from the typical propagation direction of post-sunset EPBs. However, 
(a)

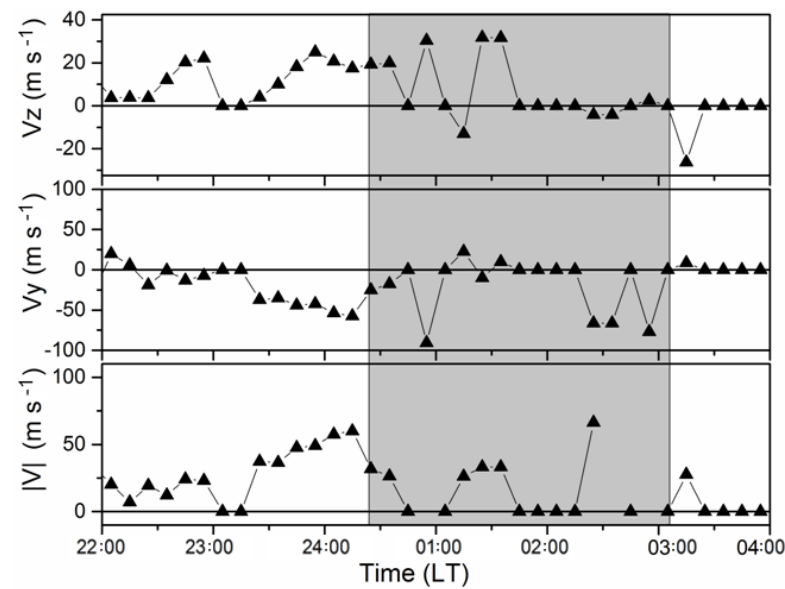

(b)

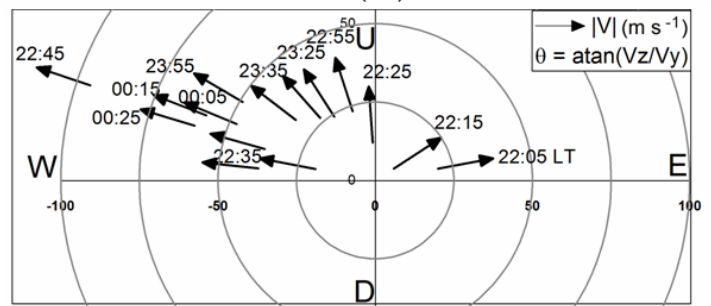

(c)

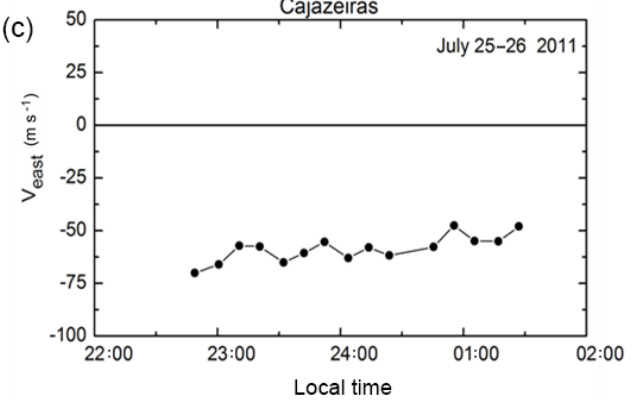

Figure 6. (a) Vertical $\left(V_{z}\right)$, zonal $\left(V_{y}\right)$, and total $(|V|)$ drift velocities on 25-26 July 2011 over FZ from 22:00 to 04:00 LT. $V_{y}>0$ is eastward. (b) Vector diagram showing the variations and directions of the mean total drift velocity of the irregularities seen as spread $\mathrm{F}$ in ionograms. For clarity, the $|V|$ values are represented by the arrow start points. (c) Zonal drift velocities obtained from the depletions seen on the OI $630.0 \mathrm{~nm}$ emission images obtained at $\mathrm{CZ}$ on 25-26 July 2011 for comparison.

this atypical propagation can be a characteristic of postmidnight depletions and needs further investigation with a longterm airglow database. The depletions also propagated over $\mathrm{CZ}(350 \mathrm{~km}$ south of FZ) with mean westward velocities $\sim 60 \mathrm{~m} \mathrm{~s}^{-1}$, which are similar to the propagation velocities of the irregularities observed with the digisonde at FZ. Some authors have demonstrated that EPBs can also present westward propagation after midnight during quiet times (Paulino et al., 2010; Sobral et al., 2011). However, those studies reported that the depletions associated with EPBs should first present movement to the east earlier in the evening and reversal westward at later hours. This is not the case for the structures presented in this work since there are no deple-

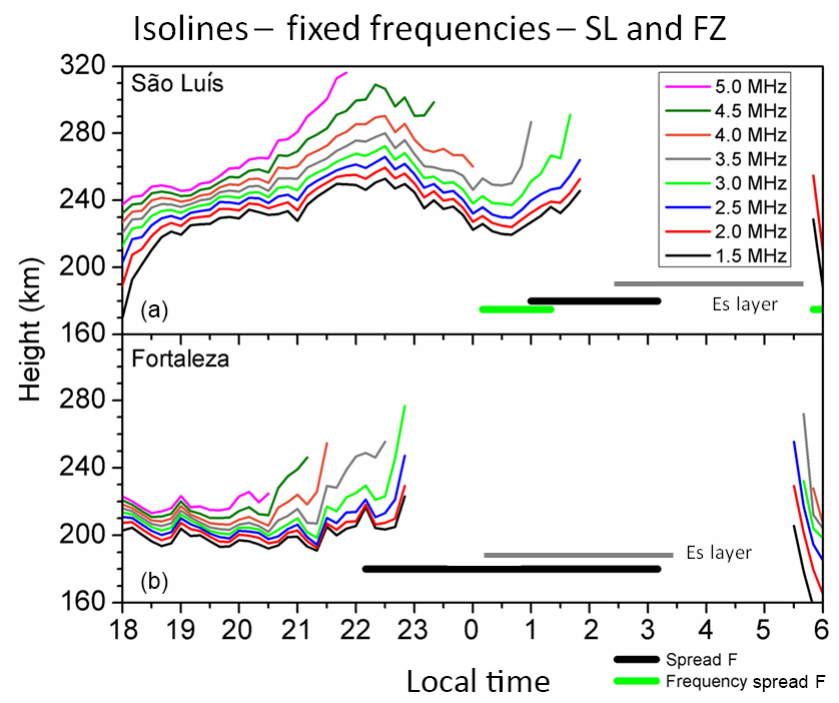

Figure 7. Oscillations in the real height of the $F$ layer at fixed frequencies (1.5 to $5.0 \mathrm{MHz}$ ) before the spread F in São Luís (a) and Fortaleza (b).

tions in the OI $630.0 \mathrm{~nm}$ images propagating eastward earlier in the evening.

Moreover, Sobral et al. (2011) interpreted westwardtraveling plasma bubbles (WTPBs) observed in the same region as associated with westward zonal thermospheric winds (simulated results). On the other hand, Fisher et al. (2015) presented a climatological study of quiet-time thermospheric winds and temperatures with measurements of the OI $630.0 \mathrm{~nm}$ airglow emission spectral line shape over the same region. They noticed that during low solar activity $(\mathrm{F} 10.7<125 \mathrm{sfu})$, the zonal and meridional winds are, on average, negligible in postmidnight hours. It is possible that these differences could be attributed to departures from the wind system, which could be responsible for the F-layer uplifts and plasma instability or irregularity development.

\subsection{Spread $F$ in ionograms}

As mentioned before, spread-F echoes in ionograms generally appear first at the low-frequency end, as satellite traces, evolving into spread-F echoes extended in frequency and range. These characteristics were not seen in the present study. In this work, the reflected echoes observed in the ionograms first came from oblique directions and at heights that could possibly be considered higher than those observed overhead. The spread echoes appear at the higher-frequency edge of the $\mathrm{F}$ layer, with a top frequency higher than the layer critical frequency. Subsequently, the low-frequency edge of the cusp merges with the main trace, while the baseline of the spread-F traces gradually decreases in height. Anomalous traces in F-layer ionograms, such as cusps or "spurs", were described in earlier studies as associated with traveling disturbances in the ionosphere. Munro and Heisler (1956) 


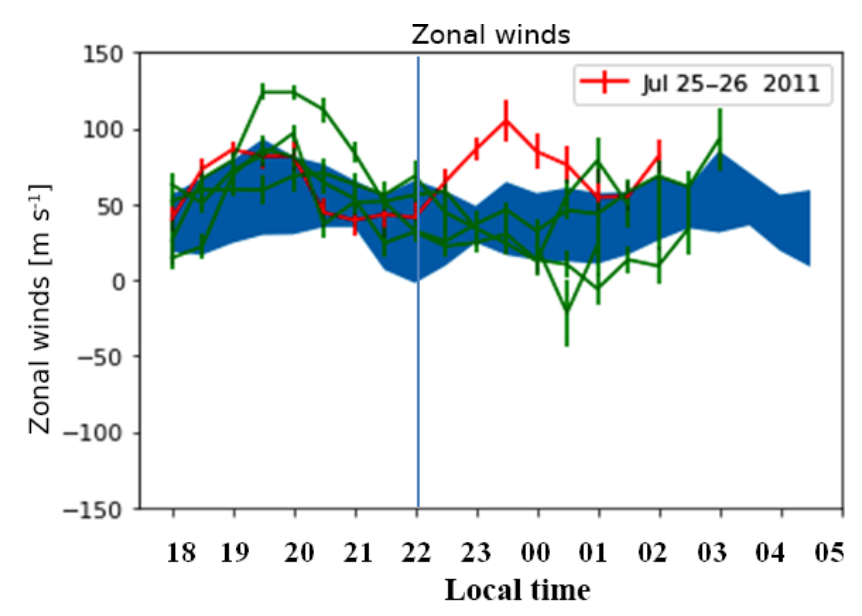

FZ, followed by their occurrence over SL (a western site in relation to FZ), suggested that they propagated westward. Late to pre-dawn spread $\mathrm{F}$ was also reported by MacDougall et al. (1998) for solstices in the Brazilian sector. However, they considered the occurrence of late-time spread $\mathrm{F}$ during the December solstice at Fortaleza as patches of ionization, which cause spread echoes at the high-frequency end or the frequency spread F. They also concluded that the echoes did not come from overhead structures but the east or west directions.

\subsection{Postmidnight irregularities and F-region background conditions}

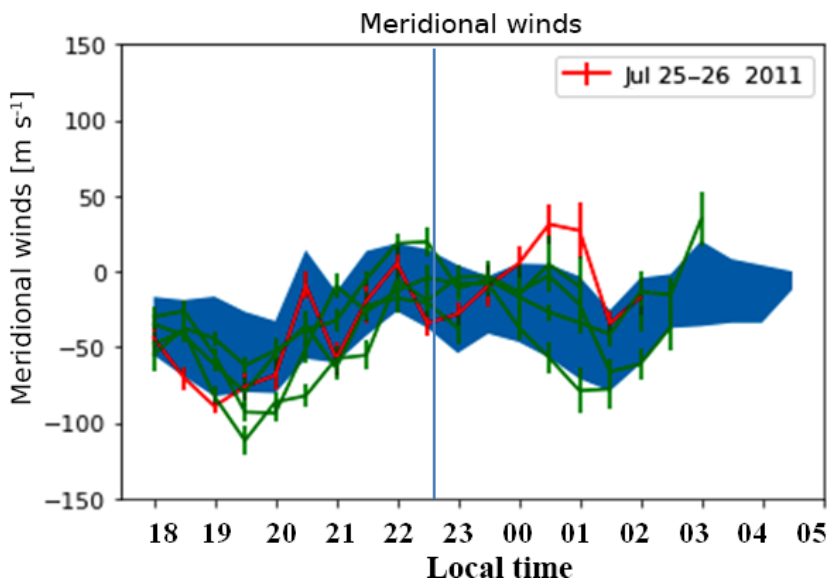

Figure 8. Measured zonal and meridional winds in CZ, Brazil, on 25-26 July 2011. The shaded region is the monthly average with standard deviation; the green lines are the mean winds on 2526 July (mean of $2 \mathrm{~d}$ ), and the red line is for 25-26 July.

and Heisler (1958) have observed the occurrence of anomalous traces in ionograms and attributed them to manifestations of TIDs. As is well known, TIDs can be described as frontal gravity waves propagating horizontally in the ionosphere, causing increases and decreases in ionization, i.e., horizontal gradients in ionization. According to Munro and Heisler (1956), changes in ionization would be responsible for the anomalous traces in the F-layer ionogram. Similar occurrences were reported by Ratcliffe (1956) for ionograms from Huancayo, Peru. Calvert and Cohen (1961) have pointed out that some spread-F traces observed over Huancayo presented characteristics similar to frequency spread $\mathrm{F}$ from "temperate" latitudes, which is mainly associated with TIDs. Also, they studied distinct configurations of spread $\mathrm{F}$ with echoes coming from oblique directions, similar to what is presented in this work. The oblique echoes observed in ionograms alone could not provide their zonal direction (from east or west). However, additional directional information provided from the drift-mode sounding of the digisonde (DPS-4) and their appearance first in the ionograms over

As is well known, poor alignment between the sunset terminator and the magnetic field lines during the June solstice in Brazil is responsible for the low occurrence rate of postsunset spread F and EPBs, since the vertical plasma drifts are very weak. However, an occurrence peak of late-night spread-F and/or plasma irregularities is observed in the June solstice, especially around midnight and postmidnight. For this, it is necessary to have an F-layer uplift, which creates favorable conditions for the development of the RT instability. These conditions are not entirely understood, and they have been discussed by several authors (McDougall et al., 1998; Nicolls et al., 2006; Abdu et al., 2009; Nishioka et al., 2012; Yokoyama et al., 2011; Ajith et al., 2016).

During high solar activity, the longitudinal variation of the declination angle is predominant on the F-layer vertical drift and the occurrence of plasma irregularities, while it is not essential during solar minimum. During low solar activity and/or a solar minimum, in the absence of geomagnetic disturbances, the seeding processes related to gravity waves seem to be more critical, especially when the prereversal enhancement (PRE) amplitude is small or absent (Balachandran et al., 1992; Abdu et al., 2009). In this way, we should address the conditions that precede the occurrence of the postmidnight irregularities observed in this work. It is noted that spread-F traces associated with plasma irregularities were detected first at oblique directions at least $500 \mathrm{~km}$ east or west from the station, as seen in the directograms in Fig. 5, which we can consider to be ionospheric conditions favorable in a wide longitudinal range.

\subsubsection{Thermospheric winds}

Nicolls et al. (2006) discussed the nocturnal F-layer uplifts associated with the secondary maximum of the spread-F occurrence rate in low solar activity. As is well understood, the nocturnal westward electric field is responsible for the downward movement of the F layer. During solar minimum, these electric fields can be easily reversed by a weak geomagnetic disturbance. However, in the absence of the geomagnetic disturbance, which is the case studied in this work, other sources should be considered. Analyzing F-layer uplifts for different 
conditions of solar activity, Nicolls et al. (2006) verified that during downward F-layer movement (decreasing westward electric field), even a small contribution of a meridional equatorward wind $\left(\sim 30 \mathrm{~m} \mathrm{~s}^{-1}\right)$ could lead the $\mathrm{F}$ layer to higher heights, triggering the RT instability.

Moreover, it was discussed that neutral winds could not uplift the equatorial plasma directly, but they are sources of meridional advection (movement) for plasma driven by a latitudinal gradient in electron density and responsible for Flayer uplifts. They concluded that the uplifts could be due to the decreasing, not to the reversal, of the westward zonal electric field associated with departures in the wind system related to the midnight temperature maximum (MTM), recombination processes, and the plasma flux. In this way, we analyze the zonal and meridional neutral wind variation in Fig. 8 in order to verify that there are suitable conditions for F-layer uplift. As is observed in Fig. 8 (top panel), the zonal wind is $\sim 100 \mathrm{~m} \mathrm{~s}^{-1}$ just before midnight, while the meridional wind (equatorward) is $\sim 30 \mathrm{~m} \mathrm{~s}^{-1}$ just after midnight (bottom panel). There is evidence that the mean equatorward meridional winds have kept the $\mathrm{F}$ layer at higher altitudes long enough to trigger RT instability development.

\subsubsection{Recombination processes - Rayleigh-Taylor instability growth rate}

Nishioka et al. (2012) discussed the causes of the postmidnight uplifts that occurred during winter in Chumphon, Thailand (low latitude), and the postmidnight field-aligned irregularities (FAIs) in Kototaband, Indonesia (equatorial region). As is well known, the zonal electric field is westward during the night, as the vertical drift ExB is downward. This condition leads to a negative RT instability growth rate. In this way, it is crucial to address the importance of the term $g / v_{\text {in }}$ in the linear growth rate of RT instability and the recombination processes, as shown in Eq. (1):

$\gamma=\left(\frac{E}{B}+\frac{g}{v_{\text {in }}}\right) \frac{1}{L}$

where $E$ is the electric field, $B$ is the magnetic field, $g$ is the acceleration of gravity, $\nu_{\text {in }}$ is the ion-neutral collision frequency, and $L$ is the scale length of the vertical gradient of the F-region plasma density. At night, the zonal electric field is westward, as the growth rate can be negative; i.e., the Flayer bottom side is stable. On the other hand, the term $g / \nu_{\text {in }}$ may increase in the following conditions: (1) $v_{\text {in }}$ is proportional to the neutral density, $n$, where $n$ is smaller during the night than the day; (2) $v_{\text {in }}$ is smaller at higher altitudes owing to the decrease in $n$ with the height; and (3) $v_{\text {in }}$ is smaller during low solar activity. Therefore, under the appropriate conditions, the RT growth rate can be positive, although small, as is observed in this work. To understand the recombination processes as a source of F-layer uplift, the F-layer bottom side should be considered eroded if it is at lower altitudes (at $\sim 300 \mathrm{~km}$ ), such as when there is a decrease in peak density

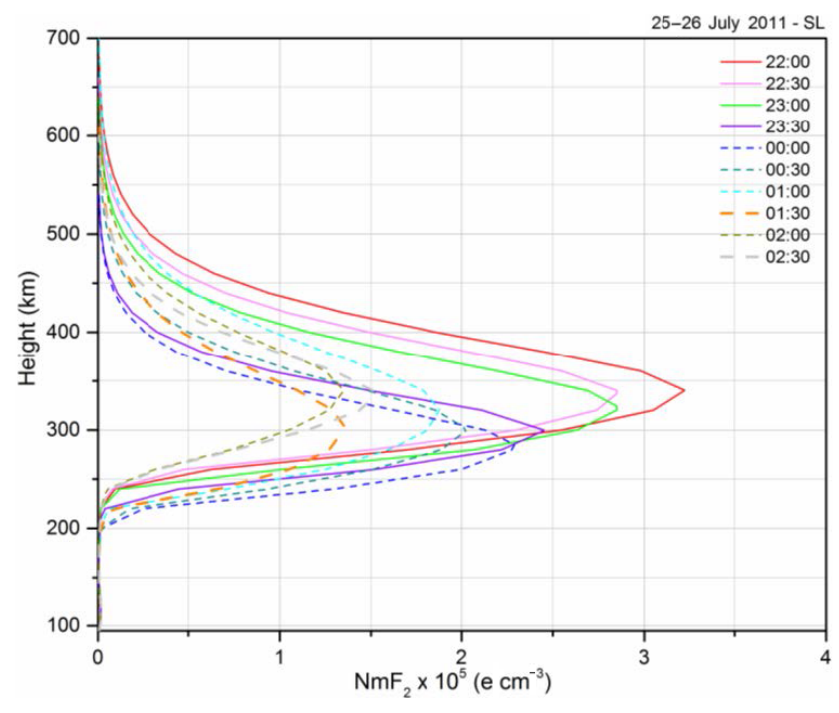

Figure 9. F-layer plasma density profile for 25-26 July derived from digisonde data and SAO Explorer data for several hours (LT).

and an increase in F-layer peak height. For clarity, we present the F-layer density profiles in Fig. 9, taken from measurements using the digisonde installed in SL. It is possible to observe that from 22:00 to 00:00 LT, the F-layer peak height and peak density decrease. As the F-layer bottom side is at a lower height, an apparent F-layer uplift is observed, which can be attributed to the recombination process at the bottom side.

\subsubsection{Es-layer electric fields}

The role of the Es layer has been considered as a possible cause for late-time RT instability development. The lowlatitude Es layer can provide a sufficient polarization electric field that maps to the equatorial F-layer bottom side, causing F-layer uplift, as pointed out by Yizengaw et al. (2013). They interpreted the occurrence of late plasma irregularities and EPBs over the African coast during the same period of this work, the June solstice 2011, and discussed the fact that during quiet geomagnetic nights, there were favorable conditions for the action of polarization electric fields associated with low-latitude Es-layer instability, which mapped to the equatorial $\mathrm{F}$ layer along the geomagnetic field lines, seeding RT instability and irregularities. In fact, in this work, we can observe the occurrence of the Es layer at both quasiequatorial stations FZ and SL at around 00:00 and 02:50 LT, respectively. However, the influence of Es layers on late-time F-layer uplift in this work is not clear since they occur at the same location as the spread F. Their influence on the postmidnight spread F during solar minimum is worthy of investigation in further work. 


\subsubsection{Mesoscale traveling ionospheric disturbances (MSTIDs) and gravity waves (GWs)}

MSTIDs have been reported at Brazilian low latitudes using airglow and ionosonde (Candido et al., 2008, 2011; Pimenta et al., 2008). They appear as large-scale dark bands aligned from northeast to southwest, propagating northwestward, mainly during low solar activity, and are associated with electrodynamic forces at midlatitudes (Perkins instability); they can also be associated with the propagation of gravity waves at ionospheric heights at low latitudes or in the equatorial region. If they propagate at equatorial ionospheric heights, they can be seen as oscillations in the Flayer bottom side and can trigger RT instability and plasma bubbles. In this work, the plasma irregularities seen by the ionosonde are preceded by small oscillations in the F-layer bottom $\left(h^{\prime} \mathrm{F}\right)$ and peak heights $(h m \mathrm{~F} 2)$. However, oscillations are usually observed in the F-layer bottom side and should be carefully considered in order to establish if they are associated with GWs. Generally, they are considered associated with GW if a downward phase propagation is observed in the fixed frequency (isolines) plots; i.e., the oscillations are seen first in the higher frequencies. Figure 7 shows the occurrence of oscillations in the $\mathrm{F}$ layer through some fixed frequencies (isolines) at both stations FZ and SL, although the downward propagation is not precisely apparent. On the other hand, the spread-F pattern observed in this work is quite similar to those reported by Candido et al. (2011) during the descending phase and the solar minimum at low latitudes in $\mathrm{CP}$. This feature could suggest that they are caused by lowlatitude MSTIDs propagating equatorward or associated with the action of polarization electric fields mapping from lowlatitude MSTID structures to the equatorial F-layer bottom side. This kind of event was reported by Miller et al. (2009), who studied the occurrence of EPBs on the same night of the occurrence of MSTIDs propagating at midlatitudes and attributed them to the action of the electric field from these MSTIDs in the F-layer region. However, the depletions observed in the OI $630 \mathrm{~nm}$ emission (Fig. 3) present distinct features (propagation direction) like those associated with MSTIDs coming from low latitudes reported by Candido et al. (2011). Also, they are not similar to the depletions associated with typical EPBs, which propagate eastward. Recent results by Takahashi et al. (2018) reported the occurrence of equatorial MSTIDs in high solar activity conditions (20142015), which were associated with periodic plasma bubbles in the total electron content (TEC) maps in the same region. They showed evidence of tropospheric sources for the development and propagation of GWs at ionospheric heights.

Finally, we should address the fact that, as shown in Figs. 2 and 7, late height rise (in both $h^{\prime} \mathrm{F}$ and $h m \mathrm{~F} 2$ ) with smalleramplitude waves is observed at SL starting at $\sim 21: 00$ LT when the base height $\left(h^{\prime} \mathrm{F}\right)$ increased to $>250 \mathrm{~km}$. Such a condition can be suitable for the growth of RT instability. Over FZ, a similar sequence of variations occurred starting at $\sim 20: 00 \mathrm{LT}$ in $h m \mathrm{~F} 2$. Notice that $h^{\prime} \mathrm{F}$ and $h m \mathrm{~F} 2$ values were significantly smaller than those at SL. However, it is notable that the oscillations in the F-layer heights, especially in $h m \mathrm{~F} 2$ (with a period of around $40 \mathrm{~min}$ ), that preceded the spread-F traces (at both sites) are significantly higher in amplitude at FZ than at SL. This aspect can be noted in more detail in the isoline plots of plasma frequencies presented in Fig. 7, where the height oscillations show larger amplitudes and occur at earlier local times at FZ than at SL. Such oscillations may be associated with gravity waves propagating to ionospheric heights with preferential propagating directions to the northeast and southeast, as recently reported by Paulino et al. (2016). These oscillations are indicative of seed perturbations that lead to spread-F irregularity development through the RT mechanism. Depending upon the amplitude of the seed perturbation, even small increases in the F-layer height that marked this period could be capable of seeding RT instability and consequently generating the spread-F irregularities (see, for example, Abdu et al., 2009). To explain the nonlocal origin of the spread-F traces, as observed at both sites, it will be necessary to assume that the precursor conditions that existed at SL and FZ must have continued to exist at a longitude extending further eastward of Fortaleza, perhaps with some increase in intensity, so that the irregularities generated therein and drifting westward could be the origin of the oblique spread-F trace first observed over FZ and later over SL.

It is plausible to consider the depletions observed in this work to be associated with atypical EPBs triggered by GWsMSTIDs at locations to the east of FZ and SL or with F-layer uplifts caused by departures from the wind system simultaneously with a weakening of the westward zonal electric field (not shown here) during low solar activity. We should note that the observational techniques used in this work are complementary and validate each other to identify "anomalous" spread-F patterns associated with plasma irregularities and depletions, and they can also help us understand the ionosphere during low solar activity. The drift mode is advantageous and suitable for tracking plasma irregularities and their evolution in the absence of other techniques.

\section{Summary and conclusions}

In this paper, we have presented and discussed an unusual spread-F pattern associated with unusual depletions on the OI $630 \mathrm{~nm}$ airglow emission observed during geomagnetically quiet conditions during the June solstice of 2011 over the equatorial region in Brazil. We summarize our findings as follows.

1. The unusual spread-F pattern studied in this work presents a distinct feature from those usually observed at post-sunset hours, with spread $\mathrm{F}$ appearing first at the higher-frequency edge of the F-layer trace to further develop into a mixed (frequency and range) spread F. 
2. The spread $\mathrm{F}$ and depletions occurred during lowplasma-density conditions, geomagnetically quiet nights, and low solar activity; they propagated westward. For the studied case, there is no evidence of previous depletions propagating eastward.

3. The processes to generate spread $\mathrm{F}$ at equatorial latitudes during quiet times seem to be associated with later-time F-layer uplifts, possibly caused by departures in the neutral wind system. In turn, departures in the neutral wind system may be caused by increased auroral activity, which in this present study may be associated with the occurrence of a short-duration event of high-speed stream (this possible influence is the subject of an ongoing study). Moreover, departures of the wind system associated with a weakening of the westward electric field, or with the propagation of GWs at ionospheric heights, favor the development of late-time RT instability. Further studies including simulations are in progress.
4. The spread-F event discussed here presents characteristics similar to those of earlier cases reported for the low latitudes in CP (around the south crest of the EIA) during the June solstice of solar minimum 2008-2009 by Candido et al. (2011), which were interpreted as the signature of the propagation of midlatitude MSTIDs in the ionograms.

5. The instrumental approach in this work seems to be suitable for further ionospheric studies, modeling, and forecasting during low solar activity.

Data availability. The processed data used in this work can be requested from the author, Claudia M. N. Candido, by email: claudia.candido@inpe.br. The authors thank the EMBRACE/INPE program for the digisonde raw data, which can be downloaded from http://www.inpe.br/embrace (last access: 30 June 2019). The airglow and Fabry-Pérot data should be requested from the author, Jonathan Makela, by email: jmakela@illinois.edu. 


\section{Appendix A: Abbreviations}

$\begin{array}{ll}\text { SL } & \text { São Luís } \\ \text { FZ } & \text { Fortaleza } \\ \text { CZ } & \text { Cajazeiras } \\ \text { CP } & \text { Cachoeira Paulista } \\ \text { DPS } & \text { Digital portable sounder } \\ \text { FPI } & \text { Fabry-Pérot interferometer } \\ \text { EPBs } & \text { Equatorial plasma bubbles } \\ \text { PMIs } & \text { Postmidnight plasma irregularities } \\ \text { RT } & \text { Rayleigh-Taylor } \\ \text { EIA } & \text { Equatorial ionization anomaly } \\ \text { MSTIDs } & \text { Mesoscale traveling ionospheric disturbances } \\ \text { FAIs } & \text { Field-aligned irregularities } \\ \text { TIDs } & \text { Traveling ionospheric disturbances } \\ \text { SFU } & \text { Solar flux unity } \\ \text { LT } & \text { Local time } \\ \text { UT } & \text { Universal time } \\ \text { MTM } & \text { Midnight temperature maximum } \\ \text { GWs } & \text { Gravity waves }\end{array}$


Author contributions. CMNC wrote the paper and plotted the graphics of the ionospheric parameters. FBG contributed with part of the graphics and revised the paper. JS, ISB, EC, MAA, NB, ZL, and $\mathrm{CW}$ read and made suggestions regarding the paper. JM and NC provided the airglow figures and Fabry-Pérot data and plots, as well as reading the paper and suggesting corrections. All the authors read, commented, and made suggestions regarding the work and agreed with the content and submission of this paper.

Competing interests. The authors declare that they have no conflict of interest.

Acknowledgements. Claudia M. N. Candido thanks the ChinaBrazil Joint Laboratory for Space Weather, CBJLSW, for the postdoctoral fellowship program. The authors thank the EMBRACE/INPE/MCTIC program for providing ionospheric data for this work. We are grateful to the Universidade Federal de Campina Grande and Ricardo A. Buriti for support regarding the imaging systems installed at Cajazeiras. Narayan Chapagain thanks the NASA Living with a Star Heliophysics Postdoctoral Fellowship Program, administered by the University Corporation for Atmospheric Research (UCAR). Work at the University of Illinois at UrbanaChampaign was performed in collaboration with John Meriwether at Clemson University.

Financial support. This research has been supported by the ChinaBrazil Joint Laboratory for Space Weather (CBJLSW) and a Brazilian funding agency (CNPq, grant no. 64537/2015-5). Jiankui Shi was supported by the National Natural Science Foundation of China (NSSC, grant nos. 41474137 and 1674145). Work at the University of Illinois at Urbana-Champaign was supported by National Science Foundation CEDAR (grant no. AGS 09-40253).

Review statement. This paper was edited by Steve Milan and reviewed by two anonymous referees.

\section{References}

Abalde, J. R., Sahai, Y., Fagundes, P. R., Becker-Guedes, F., Bittencourt, J. A., Pillat, V. G., Lima, W. L. C., Candido, C. M. N., and de Freitas, T. F.: Day-to-day variability in the development of plasma bubbles associated with geomagnetic disturbances, J. Geophys. Res., 114, A04304, https://doi.org/10.1029/2008JA013788, 2009.

Abdu, M. A., Bittencourt, J. A., and Batista, I. S.: Magnetic declination control of the equatorial $\mathrm{F}$ region dynamo field development and spread F, J. Geophys. Res., 86, 11443-11446, 1981 a.

Abdu, M. A., Batista, I. S., and Bittencourt, J. A.: Some characteristics of spread $\mathrm{F}$ at the magnetic equatorial station Fortaleza, J. Geophys. Res., 86, 6836-6842, 1981b.

Abdu, M. A., Sobral, J. H. A., Batista, I. S., Rios, V. H., and Medina, C.: Equatorial spread F occurrence statistics in the American lon- gitudes: Diurnal, seasonal and solar cycle variations, Adv. Space Res., 22, 851-854, 1998.

Abdu, M. A., Batista, I. S., Reinisch, B. W., de Souza, J. R., Sobral, J. H. A., Pedersen, T. R., Medeiros, A. F., Schuch, N. J., de Paula, E. R., and Groves, K. M., Conjugate Point Equatorial Experiment (COPEX) campaign in Brazil: Electrodynamics highlights on spread $\mathrm{F}$ development conditions and day-to-day variability, J. Geophys. Res., 114, A04308, https://doi.org/10.1029/2008JA013749, 2009.

Ajith, K. K., Tulasi Ram, S., Yamamoto, M., Otsuka, Y., and Niranjan, K.: On the fresh development of equatorial plasma bubbles around the midnight hours of June solstice, J. Geophys. Res.Space, 121, 9051-9062, https://doi.org/10.1002/2016JA023024, 2016.

Balachandran Nair, R., Balan, N., Bailey, G. J., and Rao, P. B.: Spectra of the ac electric fields in the post-sunset F-region at the magnetic equator, Planet. Space Sci., 40, 655-662, https://doi.org/10.1016/0032-0633(92)90006-A, 1992.

Balan, N., Jayachandran, B., Balachandran Nair, R., Namboothiri, S. P., Bailey, G. J., and Rao, P. B.: HF Doppler observations of vector plasma drifts in the evening F-region at the magnetic equator, J. Atmos. Terr. Phys., 54, 1545-1554, 1992.

Balan N., Liu, L. B., and Le, H. J.: A brief review of equatorial ionization anomaly and ionospheric irregularities, Earth Planet. Phys., 2, 1-19, https://doi.org/10.26464/epp2018025, 2018.

Batista, I. S., de Medeiros, R. T., Abdu, M. A., and de Souza, J. R.: Equatorial Ionospheric Vertical Plasma Drift Model over the Brazilian Region, J. Geophys. Res., 101, 10887-10892, 1996.

Batista, I. S., Abdu, M. A., Carrasco, A. J., Reinisch, B. W., Paula, E. R., Schuch, N. J., and Bertoni, F.: Equatorial spread F and sporadic E-layer connections during the Brazilian Conjugate Point Equatorial Experiment (COPEX), J. Atmos. Sol.-Terr. Phy., 70, 1133-1143, https://doi.org/10.1016/j.jastp.2008.01.007, 2008.

Booker, H. G. and Wells, H. W.: Scattering of radio waves in the F-region of the ionosphere, Terr. Magn. Atmos. Electr., 43, 249256, https://doi.org/10.1029/TE043i003p00249, 1938.

Bowman, G. G.: A comparison of nighttime TID characteristics between equatorial ionospheric anomaly crest and midlatitude regions, related to Spread F occurrence, J. Geophys. Res., 106, 1761-1769, https://doi.org/10.1029/2000JA900123, 2001.

Breit, G. and Tuve, M. A.: A Test for the Existence of the Conducting Layer, Phys. Rev., 28, 554-575, 1926.

Calvert, W. and Cohen, R.: Interpretation and Synthesis of Certain Spread-F Configurations Appearing on Equatorial Ionograms, J. Geophys. Res., 66, 3125-3132, 1961.

Candido, C. M. N., Pimenta, A. A., Bittencourt, J. A., and BeckerGuedes, F.: Statistical analysis of the occurrence of mediumscale traveling ionospheric disturbances over Brazilian low latitudes using OI $630.0 \mathrm{~nm}$ emission all-sky images, Geophys. Res. Lett., 35, L17105, https://doi.org/10.1029/2008GL035043, 2008.

Candido, C. M. N., Batista, I. S., Becker-Guedes, F., Abdu, M. A., Sobral, J. H. A., and Takahashi, H.: Spread F occurrence over a southern anomaly crest location in Brazil during June solstice of solar minimum activity, J. Geophys. Res., 116, A06316, https://doi.org/10.1029/2010JA016374, 2011.

Chapagain, N. P., Makela, J. J., Meriwether, J. W., Fisher, D. J., Buriti, R. A., and Medeiros, A. F.: Comparison of Nighttime Zonal Neutral Winds and Equatorial Plasma Bubble 
Drift Velocities over Brazil, J. Geophys. Res., 117, A06309, https://doi.org/10.1029/2012JA017620, 2012.

Dao, T., Otsuka, Y., Shiokawa, K., Tulasi Ram, S., and Yamamoto, M.: Altitude development of postmidnight $\mathrm{F}$ region field-aligned irregularities observed using Equatorial Atmosphere Radar in Indonesia, Geophys. Res. Lett., 43, 1015-1022, https://doi.org/10.1002/2015GL067432, 2016.

Fisher, D. J., Makela, J. J., Meriwether, J. W., Buriti, R. A., Benkhaldoun, Z., Kaab, M., and Lagheryeb, A.: Climatologies of nighttime thermosphericwinds and temperatures fromFabryPerot interferometer mea-surements: From solar minimumto solar maximum, J. Geophys. Res.-Space, 120, 6679-6693, https://doi.org/10.1002/2015JA021170, 2015.

Galkin, I. A., Khmyrov, G. M., Reinisch, B. W., and McElroy, J.: The SAOXML 5: New format for ionogram-derived data, in Radio Sounding and Plasma Physics, AIP Conf. Proc. 974, 160$166,2008$.

Heisler, L. H.: Anomalies in ionosonde records due to traveling ionospheric disturbances, Austr. J. Phys., 11, 79-90, 1958.

Li, G., Ning, B., Abdu, M. A., Yue, X, Liu, L., Wan, W., and Hu, L.: On the occurrence of postmidnight equatorial $F$ region irregularities during the June solstice, J. Geophys. Res., 116, A04318, https://doi.org/10.1029/2010JA016056, 2011.

MacDougall, J., Abdu, M. A., Batista, I., Buriti, R., Medeiros, A. F., Jayachandran, P. T., and Borba, G.: Spaced transmitter measurements of medium-scale traveling ionospheric disturbances near the equator, Geophys. Res. Lett., 38, L16806, https://doi.org/10.1029/2011GL048598, 2011.

MacDougall, J. W., Abdu, M. A., Jayachandran, P. T., Cecile, F., and Batista, I. S.: Presunrise spread F at Fortaleza, J. Geophys. Res., 103, 23415-23425, 1998.

Makela, J. J. and Miller, E. S.: Optical observations of the growth and day-to-day variability of equatorial plasma bubbles, J. Geophys. Res., 113, A03307, https://doi.org/10.1029/2007JA012661, 2008.

Makela, J. J., Miller, E. S., and Tallat, E.: Nighttime medium-scale traveling ionospheric disturbances at low geomagnetic latitudes, Geophys. Res. Lett., 37, L24104, https://doi.org/10.1029/2010GL045922, 2010.

Miller, E. S., Makela, J. J., and Kelley, M. C.: Seeding of equatorial plasma depletions by polarization electric fields from middle latitudes: Experimental evidence, Geophys. Res. Lett., 36, L18105, https://doi.org/10.1029/2009GL039695, 2009.

Munro, G. H. and Heisler, L. H.: Cusp-Type Anomalies in Variable Frequency Ionospheric Records, Austr. J. Phys., 9, 343-358, 1956.

Nicolls, M. J., Kelley, M. C., Vlasov, M. N., Sahai, Y., Chau, J. L., Hysell, D. L., Fagundes, P. R., Becker-Guedes, F., and Lima, W. L. C.: Observations and modeling of post-midnight uplifts near the magnetic equator, Ann. Geophys., 24, 1317-1331, https://doi.org/10.5194/angeo-24-1317-2006, 2006.

Nishioka, M., Otsuka, Y., Shiokawa, K., Tsugawa, T., Effendy, Supnithi, P., Nagatsuma, T., and Murata, K. T.: On postmidnight field-aligned irregularities observed with a $30.8-\mathrm{MHz}$ radar at a low latitude: Comparison with F-layer altitude near the geomagnetic equator, J. Geophys. Res., 117, A08337, https://doi.org/10.1029/2012JA017692, 2012.

Otsuka, Y.: Review of the generation mechanisms of post-midnight irregularities in the equatorial and low- latitude ionosphere, Progress in Earth Planet. Sci., 5, 57, https://doi.org/10.1186/s40645-018-0212-7, 2017.

Otsuka, Y. and Ogawa, T.: Effendy, VHF radar observations of nighttime F-region field-aligned irregularities over Kototabang, Indonesia, Earth Planets Space, 61, 431-437, 2009.

Paulino, I., Medeiros, A. F., Buriti, R. A., Sobral, J. H. A., Takahashi, H., and Gobbi, D.: Optical observations of plasma bubble westward drift over Brazilian tropical region, J. Atmos. Terr. Phys, 72, 521-527, 2010.

Paulino, I., Medeiros, A. F., Vadas, S. L., Wrasse, C. M., Takahashi, H., Buriti, R. A., Leite, D., Filgueira, S., Bageston, J. V., Sobral, J. H. A., and Gobbi, D.: Periodic waves in the lower thermosphere observed by OI630 nm airglow images, Ann. Geophys. 34, 293-301, https://doi.org/10.5194/angeo-34-293-2016, 2016.

Pimenta, A. A., Amorim, D., and Candido, C. M. N.: Thermospheric dark band structures at low latitudes in the Southern Hemisphere under different solar activity conditions: A study using OI $630 \mathrm{~nm}$ emission all-sky images, Geophys. Res. Lett., 35, L16103, https://doi.org/10.1029/2008GL034904, 2008.

Ratcliffe, J. A.: Some Irregularities in the F2 Region of the Ionosphere, J. Geophys. Res., 50, 487-507, 1956.

Reinisch, B. W., Abdu, M., Batista, I., Sales, G. S., Khmyrov, G., Bullett, T. A., Chau, J., and Rios, V.: Multistation digisonde observations of equatorial spread $\mathrm{F}$ in South America, Ann. Geophys., 22, 3145-3153, https://doi.org/10.5194/angeo-22-31452004, 2004.

Reinisch, B. W., Huang, X., Galkin, I. A., Paznukhov, V., and Kozlov, A.: Recent advances in the real-time analysis of ionograms and ionospheric drift measurements with digisondes, J. Atmos. Terr. Phys., 67, 1054-1062, 2005.

Sahai, Y., Fagundes, P. R., and Bittencourt, J. A.: Transequatorial Fregion ionospheric plasma bubbles solar cycle effects, J. Atmos. Sol.-Terr. Phy., 62, 1377-1383, 2000.

Sobral, J. H. A., Abdu, M. A., Takahashi, H., Taylor, M. J., de Paula, E. R., Zamlutti, C. J., Aquino, M. G., and Borba, G. L.: Ionospheric plasma bubble climatology over Brazil based on 22 years (1977-1998) of $630 \mathrm{~nm}$ airglow observations, J. Atmos. Sol.-Terr. Phy., 64, 1517-1524, 2002.

Sobral, J. H. A., deCastilho, V. M., Abdu, M. A., Takahashi, H., Paulino, I, Gasparelo, U. A. C., Arruda, D. C. S., Mascarenhas, M., Zamlutti, C. J., Denardini, C. M., Koga, D., deMedeiros, A. F., and Buriti, R. A.: Midnight reversal of ionospheric plasma bubble eastward velocity to westward velocity during geomagnetically quiet time: Climatology and its model validation, J. Atmos. Terr. Phys., 73, 1520-1528, 2011.

Takahashi, H., Wrasse, C. M., Figueiredo, C. A. O. B., Barros, D., Abdu, M. A., Otsuka, Y., and Shiokawa, K.: Equatorial plasma bubble seeding by MSTIDs in the ionosphere, Progress in Earth and Planetary Science, 5, 32, https://doi.org/10.1186/s40645018-0189-2, 2018.

Valladares, C. E., Hanson, W. B., McClure, J. P., and Cragin, B. L.: Bottomside sinusoidal irregularities in the equatorial F region, J. Atmos. Sol.-Terr. Phy., 88, 8025-8042, https://doi.org/10.1029/JA088iA10p08025, 1983.

Yizengaw, E., Retterer, J., Pacheco, E. E., Roddy, P., Groves, K., Caton, R., and Baki, P.: Postmidnight bubbles and scintillations in the quiet-time June solstice, Geophys. Res. Lett., 40, 55925597, https://doi.org/10.1002/2013GL058307, 2013. 
Yokoyama, T., Yamamoto, M., Otsuka, Y., Nishioka, M., Tsugawa, T., Watanabe, S., and Pfaff, R. F.: On post-midnight low latitude ionospheric irregularities during solar minimum: 1. Equatorial Atmosphere Radar and GPS TEC observations in Indonesia, J. Geophys. Res., 116, A11325, https://doi.org/10.1029/2011JA016797, 2011.
Zhan, W., Rodrigues, F., and Milla, M.: On the genesis of postmidnight equatorial spread $F$ : Results for the American/Peruvian sector, Geophys. Res. Lett., 45, 7354-7361, https://doi.org/10.1029/2018GL078822, 2018. 